Article

\title{
A Framework for Empirical Assessment of Agricultural Sustainability: The Case of Iran
}

\author{
Siavash Fallah-Alipour ${ }^{1}$, Hossein Mehrabi Boshrabadi ${ }^{1}$ * , Mohammad Reza Zare Mehrjerdi ${ }^{1}$ \\ and Dariush Hayati ${ }^{2}$ \\ 1 Department of Agricultural Economics, College of Agriculture, Shahid Bahonar University of Kerman, \\ Kerman 76169-13439, Iran; Siavash_Alipour2002@yahoo.com (S.F.-A.); zare@uk.ac.ir (M.R.Z.M.) \\ 2 Department of Agricultural Extension \& Education, College of Agriculture, Shiraz University, \\ Shiraz 71441-65186, Iran; Hayati@shirazu.ac.ir \\ * Correspondence: hmehrabi@uk.ac.ir; Tel.: +98-34-3132-2606
}

Received: 22 September 2018; Accepted: 27 November 2018; Published: 17 December 2018

\begin{abstract}
In developing countries, agricultural development is still a fundamental means of poverty alleviation, economic development and, in general, sustainable development. Despite the great emphasis on sustainable agricultural development, it seems that there are many practical difficulties towards empirical assessment of agricultural sustainability. In this regard, the present study aims to propose a comprehensive framework for the assessment of agricultural sustainability and present an empirical application of the proposed framework in south-east Iran (Kerman province). The framework is based on a stepwise procedure, involving: (1) The calculation of economic, social, environmental, political, institutional and demographic indicators, covering the actual and potential aspects of unsustainability; (2) the application of Fuzzy Pairwise Comparisons and Analytic Hierarchy Process to construct composite indicators, with the purpose of incorporating the concept of social construct into the assessment process; and (3) the application of Sustainability Maps, diagrams and Barometer of Sustainability for presenting and analyzing the results. The output of the framework is a comprehensive and yet easy-to-understand picture of agricultural sustainability numerically and visually for the selected counties of the province in 2003 and 2015 - via the variety of comparisons and rankings-which allows us to identify the weaknesses and strengths of agriculture in each county in various sustainability levels (comprehensive, overall actual and overall potential, dimensional, and base indicators). It also enables us to monitor and analyze the trends in sustainability changes over the years. By providing such information, this framework can be a useful tool to support agricultural sector decisions that would help planners and policymakers find the right path and move toward sustainability, or modify policies to stay in the right direction over time. Overall, the results suggest that the proposed framework can be an effective tool for the assessment of agricultural sustainability. Of course, it is necessary to examine and validate its capabilities through practical applications in different agricultural areas and systems.
\end{abstract}

Keywords: sustainability assessment framework; status and driver composite indices; comprehensive levels of agricultural sustainability; sustainability trend; decision support; Kerman; Iran

\section{Introduction}

Agriculture is a type of economic activity, livelihood, and provider of environmental services, contributing to the development process. It can participate, in concert with other sectors, in realizing faster growth, poverty reduction and environmental sustainability [1]. Agriculture has a special ability to reduce poverty. According to cross-country estimates, the effect of agricultural GDP growth on poverty reduction is at least twice as high as the effect of GDP growth coming from other sectors $[2,3]$. 
Estimates show that agriculture is the source of livelihoods for $86 \%$ of rural people, and generates employment opportunities for 1.3 billion smallholders and landless workers [1]. How to use natural resources in the agricultural sector-which is mostly improperly exploited-can have negative or positive environmental outcomes: Groundwater depletion, agrochemical pollution, soil exhaustion, and climate change (through the contribution of $30 \%$ greenhouse gas emissions) versus environmental services, such as carbon sequestration, watershed management and biodiversity conservation [1]. Therefore, as agricultural development has been an effective instrument for poverty eradication and economic development in developing countries during the second half of the twentieth century [4], it continues to be a fundamental tool for sustainable development and poverty reduction in the 21st century [1].

Agricultural development literature is now addressed as sustainable agriculture and sustainable agricultural development, and is tied to the concepts of sustainability and sustainable development. It is such that apart from scientists and experts involved, all people from international organizations and institutions to policymakers, governments and local and national institutions talk about sustainable agriculture and/or sustainable agricultural development-in contrast to the agricultural development. They introduce achieving it as one of their most important goals, and feel the pressing need for increased agricultural sustainability across the globe [5]. With regard to policy-making in agriculture, governments need to answer the core questions of what is sustainable agriculture, and how can we progress towards it, or maintain it? [6]. The problem is that although the idea of a sustainable agriculture has gained prominence since the release of the Brundtland Report in 1987, the concept of sustainable agriculture has still obscure and ambiguous meanings, making it extremely difficult to use and implement [7].

"Agricultural sustainability assessment is an important process for promoting the concept of sustainable agricultural systems (Astier et al., 2012) since it incorporates sustainability principles into agricultural policy planning and decision making (Pope et al., 2004)" [5] (p. 150). "Around the world the food and agriculture sectors are generally implementing over 120 voluntary sustainability assessment methods (FAO 2014)" [5] (p. 150). Seven "holistic methodologies from the larger domain of agricultural sustainability assessment which represent diversity in terms of their application and development" [5] (p. 150) are "Response-Inducing Sustainability Evaluation model (RISE) (Hani et al., 2003), Sustainability Assessment of Farming and the Environment (SAFE) (Van Cauwenbergh et al., 2007), the IDEA Method (IDEA) (Zahm et al., 2008), the Monitoring Tool for Integrated Farm Sustainability (MOTIFS) (Meul et al., 2008), Integrated Assessment of Agricultural Systems: A Component-Based Framework for the European Union (SEAMLESS) (Van Ittersum et al., 2008)" [5] (p. 150), "the MESMIS ("Spanish acronym for Indicator-based sustainability assessment framework" [5] (p. 150)) Program (Astier et al., 2012), Sustainability Assessment of Food and Agriculture Systems (SAFA) (FAO 2012) methods" [5] (pp. 150-151) that incorporate all three sustainability dimensions (with economic, social and environmental indicators) in their assessments. Table 1 summarizes these frameworks and presents some of their advantages and disadvantages.

Based on the information in Table 1 and the literature review, one can find that there are many challenges in the practical objectification of the concept of sustainability, including: From what point of view should one look at the concept of agricultural sustainability? Is this view based on certain (predetermined) principles or does it provide a specific definition of agricultural sustainability? Based on what methodological approaches can the indicators be developed? How can the summarizing indicators help to simplify and promote the concept of sustainability, decision making and policy making? Can methods (including techniques for numerical and visual summarization) be developed that help achieve sustainability assessment goals? And altogether, can we design a framework that helps to address many of these challenges and improve the assessment of agricultural sustainability? 
Table 1. Selected holistic agricultural sustainability assessment methods: Brief descriptions, some advantages and disadvantages.

\begin{tabular}{|c|c|c|c|}
\hline Methods & Brief Description & Some Advantages & Some Disadvantages \\
\hline RISE & $\begin{array}{l}\text { Developed by Swiss and international } \\
\text { participants from scientific, societal, } \\
\text { public administrations and } \\
\text { agro-industry sectors for sustainability } \\
\text { assessment at the farm level. }\end{array}$ & $\begin{array}{l}\text { Uses principles-based approaches } \\
\text { a for concept development; } \\
\text { Presents results both numerically } \\
\text { and graphically (radar charts) }\end{array}$ & $\begin{array}{l}\text { Uses only a top-down } \\
\text { approach }{ }^{b} \text { for developing } \\
\text { indicators; Does not } \\
\text { integrate information related } \\
\text { to sustainability issues } \\
\text { across scales }\end{array}$ \\
\hline SAFE & $\begin{array}{l}\text { Developed in a hierarchical, structured } \\
\text { way based on a framework of } \\
\text { principles, criteria, indicators and } \\
\text { reference values. }\end{array}$ & $\begin{array}{l}\text { Justification of indicators selection } \\
\text { are documented; Applied at field, } \\
\text { farm, landscape and national } \\
\text { levels }\end{array}$ & $\begin{array}{l}\text { Uses Triple Bottom Line } \\
\text { approach; Uses only a } \\
\text { top-down approach for } \\
\text { developing indicators }\end{array}$ \\
\hline IDEA & $\begin{array}{l}\text { Based on research conducted since } \\
1998 \text { in France. It provides an } \\
\text { operational tool for sustainability } \\
\text { assessment at the farm level. }\end{array}$ & $\begin{array}{l}\text { Uses principles-based approaches; } \\
\text { Capable of aggregating indicators; } \\
\text { Graphical results allow for } \\
\text { monitoring across regions }\end{array}$ & $\begin{array}{l}\text { Indicators were developed } \\
\text { using a top-down approach; } \\
\text { Unable to integrate issues } \\
\text { across scales; Applied only } \\
\text { at the farm level }\end{array}$ \\
\hline MOTIFS & $\begin{array}{l}\text { Based on the equal importance of } \\
\text { social, ecological and economic } \\
\text { dimensions of sustainability. }\end{array}$ & $\begin{array}{l}\text { Results presentation system } \\
\text { allows for a comprehensive } \\
\text { overview and comparison of the } \\
\text { indicators }\end{array}$ & $\begin{array}{l}\text { Unable to integrate issues } \\
\text { across scales; Not capable of } \\
\text { aggregating data and } \\
\text { indicators }\end{array}$ \\
\hline SEAMLESS & $\begin{array}{l}\text { It supports the integrated assessment } \\
\text { of agricultural systems at multiple } \\
\text { scales (field, farm, region, EU and } \\
\text { global). }\end{array}$ & $\begin{array}{l}\text { Uses both top-down and } \\
\text { bottom-up approaches; Considers } \\
\text { issues across scales in developing } \\
\text { indicators }\end{array}$ & $\begin{array}{l}\text { Uses Triple Bottom Line } \\
\text { approach; Data are not } \\
\text { normalized; Not capable of } \\
\text { aggregating indicators }\end{array}$ \\
\hline MESMIS & $\begin{array}{l}\text { It is based on an operational } \\
\text { framework building on feedback from } \\
\text { a number of case studies and examined } \\
\text { in a set of socio-ecological contexts. }\end{array}$ & $\begin{array}{l}\text { Justifications of indicators } \\
\text { selection are documented; Can use } \\
\text { both qualitative and quantitative } \\
\text { data to develop indicators }\end{array}$ & $\begin{array}{l}\text { Indicators are based only on } \\
\text { primary data sources; Does } \\
\text { not consider the issues of } \\
\text { integration across scales } \\
\text { and/or over time }\end{array}$ \\
\hline SAFA & $\begin{array}{l}\text { It is an open and participatory process } \\
\text { under FAO guidelines guiding } \\
\text { sustainability assessment that can be } \\
\text { used as a self-evaluation tool for } \\
\text { producers and food manufacturers. }\end{array}$ & $\begin{array}{l}\text { Uses principles-based approaches; } \\
\text { Uses both top-down and } \\
\text { bottom-up approaches; } \\
\text { Justifications of indicators } \\
\text { selection are documented; } \\
\text { Considers the issues of integration } \\
\text { across scales }\end{array}$ & $\begin{array}{l}\text { Not capable of aggregating } \\
\text { indicators; Validation of the } \\
\text { indicators is based on } \\
\text { comparison and expert } \\
\text { appraisal (without } \\
\text { stakeholder appraisal) }\end{array}$ \\
\hline
\end{tabular}

a "The concept of sustainability [...] is usually based on the Triple Bottom Line approach ("The sustainability issues are under the broad categories of society, economics and environment (Ahi and Searcy 2015)" [5] (p. 156)) (UN 1987) or a principles-based approach ("For example vanLoon et al. (2005) divided sustainability in six categories: Productivity, stability, efficiency, durability, compatibility, equity" [5] (p. 156)) (Gibson 2006; Pinter et al., 2012; vanLoon et al., 2005). Due to many inherent limitations of the triple-bottom-line approach including ambiguity, principles-based approaches are more appropriate for concept development, because they avoid these limitations (Pope et al., 2004)" [5] (p. 156). " "In a top-down approach, experts select the set of indicators based on their expertise (Bossel 1999), whereas in a bottom-up approach, the opinion of the stakeholders/community are considered in developing representative indicators of systems (Reed et al., 2006). [...] In terms of indicator development, the approach that gets input from both stakeholders and experts is the most effective (Fraser et al., 2006; Reed et al., 2006)" [5] (pp. 156-158). Source: Adapted from Reference [5].

Since the dryland (arid and semi-arid) ecosystems in the world are over three billion hectares (equivalent to $41 \%$ of the earth's land area) and include up to 2.5 billion people (more than one-third of the world's population), their dependent agricultural production systems are of great importance in terms of the area and intensive uses [8]. Iran, a developing country with transitional agriculture, is a country where major parts of its area are semi-arid [9]. Kerman province, the driest region in Iran [10], where agriculture is dominant and accounts for about $50 \%$ of the gross domestic product (GDP) [11], can be a good example for objectivizing the concept of agricultural sustainability in an empirical model of agricultural sustainability assessment.

In order to overcome the problems expressed in the path of practical implementation and objectivization of the concept of sustainability, the present study was carried out with the goals of: (1) Introducing a method for assessing agricultural sustainability, with its practical application details, 
for decision making and policy making purposes; (2) evaluating agricultural sustainability in Kerman province, Iran, to illustrate both the details of the introduced method and the real decision-support.

This paper is structured as follows: After this introductory section, the study area is firstly selected and its features are described in the case study section. Then, the methodology is presented in details by introducing a new framework for assessing agricultural sustainability and the step-by-step implementation of its various stages, including the design, selection, construction and calculation of the base and composite sustainability indicators. Then the most important results of empirical applications are presented and discussed. In the final section, the framework used is evaluated, as well as the conclusions of its empirical applications are summarized and finally, the model innovations and its benefits in practical applications will be summed up.

\section{Case Study}

Kerman is Iran's largest province in the southeastern part of the country, comprising 23 counties, 71 municipalities, and 151 rural districts [12]. Pistachio and wheat are the two most important crop products of this region [11]. Pistachio is one of the most important products in the country with the highest rank in non-oil exports, so that Iran has the first place in the world in terms of its cultivation, production and export [12]. Kerman province ranked first in the country's pistachio cultivation and production, with a share of $57 \%$ and $37 \%$, respectively. It is so that in 2015 , about 96,000 tons of pistachios have been harvested over 212,000 hectares [12]. In the northern, central and western parts of the province, the development of industry, services and agriculture, especially industry and cultivation of pistachios, is observed [12], which can be provincial examples of agriculture in transition in Iran. Therefore, the counties of these areas of the province, including Bardsir, Ravar, Rafsanjan, Anar, Zarand, Kuhbanan, Sirjan, Shahr-e-Babak and Kerman (the capital of the province) were selected for this study (Figure 1).

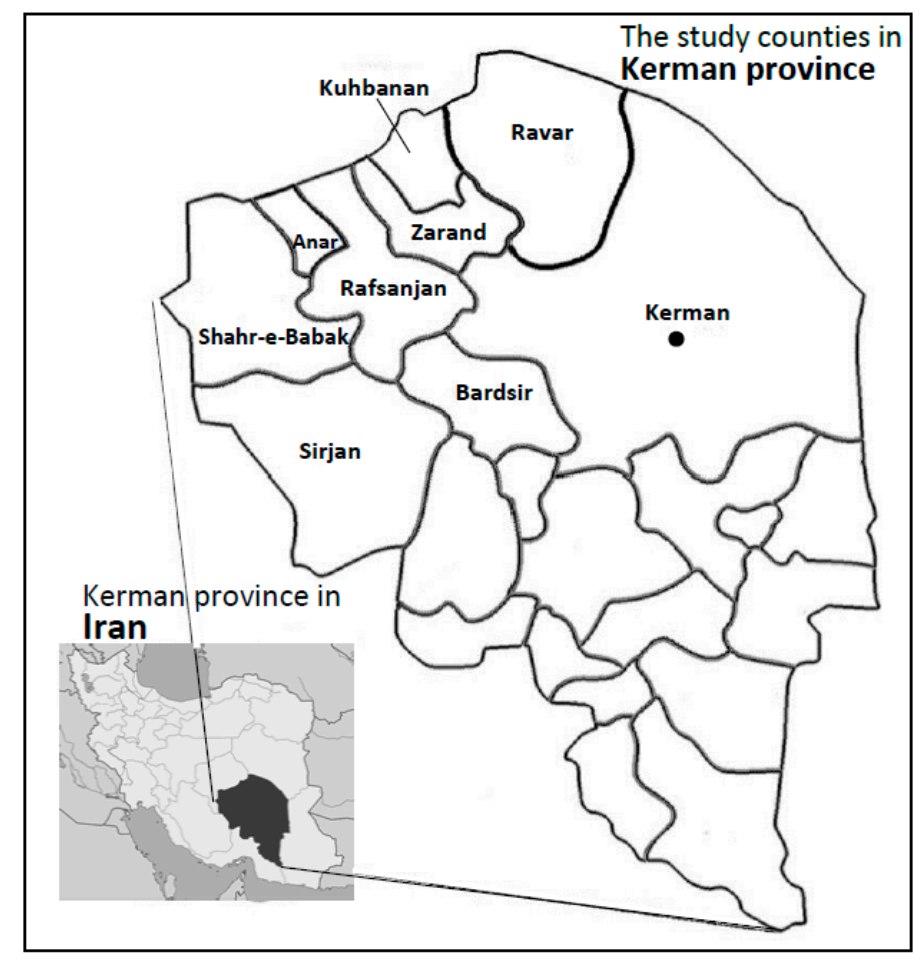

Figure 1. Location of the study counties in Kerman province, Iran (2015). Source: Reference [12].

The conventional system of pistachio and wheat cultivation in the study area is non-industrial (smallholding) irrigated agriculture. On average, about $62.5 \%$ of agricultural crop area of each county in the period from 2003 to 2015 was attributed to pistachio crop, which is higher for some counties, 
such as Rafsanjan and Anar (97\%) and Zarand and Kuhbanan (82.5\%). It should be noted that since the counties of "Rafsanjan and Anar", as well as "Zarand and Kuhbanan" in 2015 were equivalent to the individual counties of "Rafsanjan" and "Zarand" in 2003, respectively, there were no separate data for them in 2003. In this study, the combined counties were used to maintain the ability to examine the trends. In spite of climate variability, Kerman province is one of the poorest areas in terms of water resources and rainfalls; and the main sources of water supply in the region, from ancient times to the present day have been groundwater [13]. According to the drought phenomenon, rainfall in the studied area was also decreasing, so that in the period from 2003 to 2015, the average monthly precipitation in Kerman county (the largest county in Kerman province and the study area) decreased by about $17 \%$, i.e., less than $9 \mathrm{~mm}$. In the county of Shahr-e-Babak (the second largest county in the province and the studied region), rainfall even reduced to half and even less amount. Of course, during this period, the area of agricultural land under modern irrigation systems increased in (counties of) the region. Also, the average surface area of major crops (total pistachio and wheat) in the studied counties in 2015 compared to 2003 increased with the increase in the pistachios crop area. Although rural population estimates indicate an increase in population during the aforementioned period, the number of farmers in the area has decreased.

\section{Methodology}

Based on our proposed stepwise process of the Problem-oriented Status-Driver Composite Indicator-base Framework of Agricultural Sustainability Assessment (PSDCIFASA), the methodology used in this study is shown in Figure 2, which is followed by a description of each step through an empirical application.

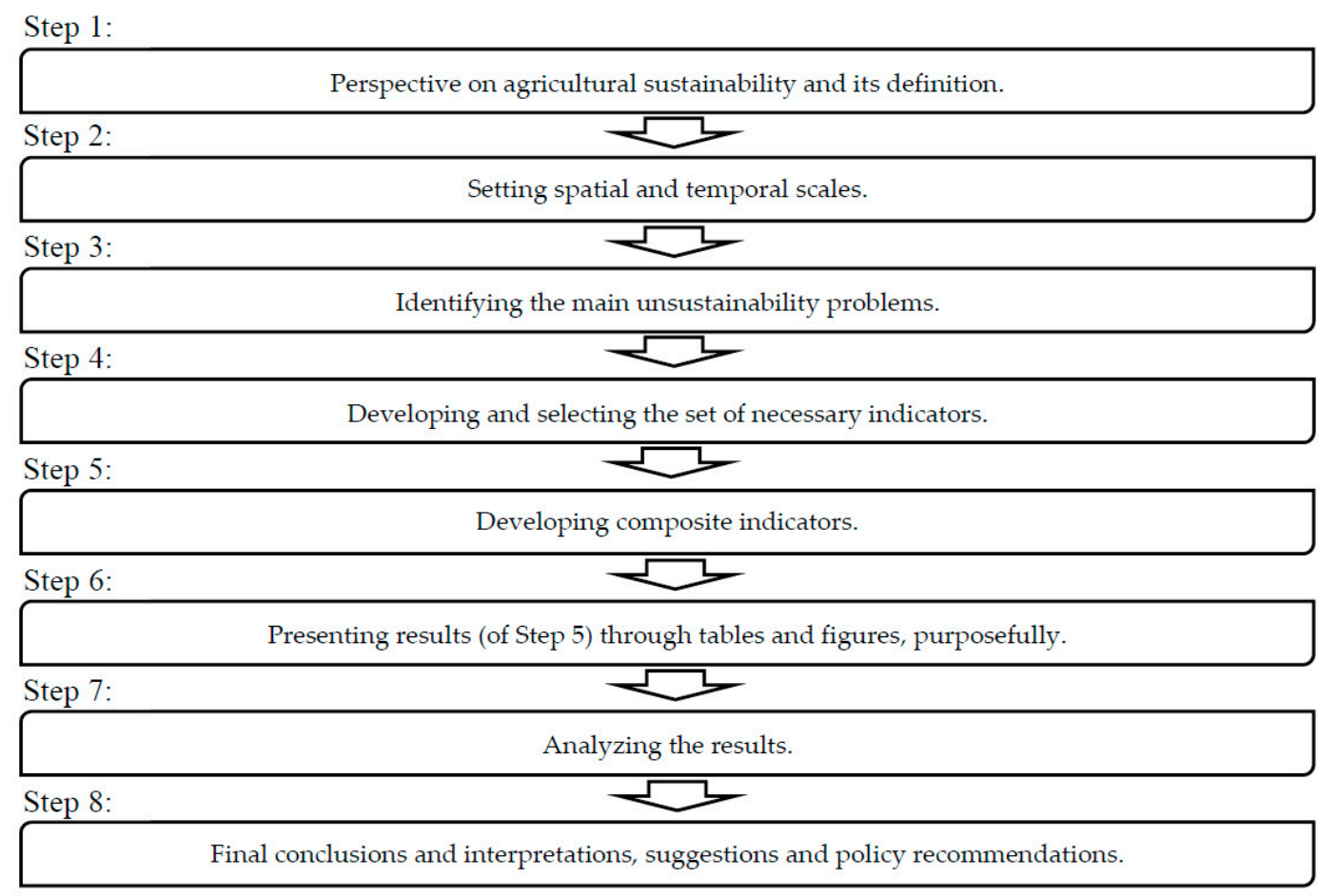

Figure 2. Methodology employed in the study. Source: Authors' own elaboration.

\subsection{Step 1: Perspective on Agricultural Sustainability and its Definition}

Our perspective on agricultural sustainability can be outlined as follows: Agricultural sustainability includes a set of features on the basis of which a given agricultural system is considered as an "agriculture for sustainable development". Accordingly, a sustainable agricultural system is 
characterized by protecting the environment, improving the appropriate agricultural production processes, and enhancing the welfare of humans (the farmer and the society) over time.

\subsection{Step 2: Setting Spatial and Temporal Scales (Social Construct)}

The assessment of sustainability based on the view of "social construct" should be operational, meaning that it should be considered as a function of societal, temporal and geographical conditions. In this study, agriculture and society are interrelated in Kerman province, forming the basis of a social construct in the evaluation of agricultural sustainability. The spatial scale of the analysis is the county that includes the abovementioned counties illustrated in Figure 1. Although the results of this study are presented in terms of county units, the required data were mainly extracted from each of the farms of these counties. The time scale is product year. In order to consider the dynamics and study of changes during the period, the product years ended in 2003 and 2015 are incorporated into the evaluation process. For this purpose, the data and information of the latest Public Agricultural Censuses in Kerman province were the statistical basis of this study, with two main objectives: (1) The Public Agricultural Census in Iran is conducted periodically and its detailed results are officially released by the Statistical Center of Iran [13]. Therefore, a relatively easy access to data and information of all farms-and not just a sample of them-will be feasible at a very low cost, which increases the accuracy and practicality of the results; (2) the collection and presentation of this periodic information (i.e., over the years) has continued from the past and is likely to continue in the future. Thus, the use of these data within the assessment framework makes a dynamic, and over-time, analysis of agricultural sustainability and its trends possible, probably even for future periods. Incorporating the concept of social constructs into the different stages of the framework was carried out through various techniques, which will be explained in each step.

\subsection{Step 3: Identifying the Main Unsustainability Problems}

In this step, according to the definition of sustainability (Step 1) and the specified social construct (Step 2), the most important sustainability issues were investigated based on the main factors and problems of agricultural unsustainability. In addition to reviewing the available resources and studies, to include social construct and its normative values, three groups of stakeholders and professionals, namely farmers, academic specialists and executive experts (from governmental organizations engaged in agriculture) were interviewed: (a) Fifteen farmers were familiar with sustainability issues that are practically affected by unsustainability problems. These farmers, who were from different counties of the province, visited the Kerman Agricultural (Jihad-e-Agriculture) Organization and/or were introduced through the organization; (b) fifteen academic staff (i.e., faculty members), who had sustainability studies and/or experience in teaching sustainable agriculture courses and were also closely associated with the issues of agricultural unsustainability in the province; (c) fifteen agricultural executive experts from various units of the Agricultural (Jihad-e-Agriculture) Organization of Kerman province, who, on the one hand, were aware of the agricultural sustainability programs and policies of the government and, on the other hand, they were directly involved with farmers.

In summary, the most important issues and problems of agricultural unsustainability in the study areas were identified as follows: (a) In relation to "environmental conservation": A multi-year drought and a reduction in rainfall, reduced water resources and water shortages associated with its lack of protection, the loss of soil and its quality, lowered water tables and soil salinity, and consequently the reduced biodiversity; (b) in relation to "improving production processes and capacity": The low efficiency and productivity of the production process of farmers, inadequate or insufficient access to knowledge and information needed by farmers; and (c) in relation to "increasing welfare": Insufficient and low income of farmers and its instability, and unfavorable employment conditions in the agricultural sector. 


\subsection{Step 4: Developing and Selecting the Set of Necessary Indicators}

Since quantitative measurements of sustainability are prerequisites of the design, implementation and control of more sustainable agricultural policies, "sustainability indicators are increasingly seen as an important tool for assessment and implementation of sustainable farming systems (Singh et al., 2012)" [8] (p. 713). Our main criteria for designing and selecting a coherent set of indicators that covered the status (actual) and driver (potential) aspects of the core problems of agricultural unsustainability in the abovementioned social construct were:

1. Scientific validity [14,15], (easy) measurability [4,14-16], policy relevance [14-16], assessment of trends over time [14], and, as much as possible, suitable for different scales (e.g., farm, district, country, etc.) [17];

2. Make use of available data $[4,14,15,18]$ in Public Agricultural Census of Iran and the Statistical Yearbook of Iran-Kerman province, over time (i.e., from past to present and possibly future);

3. Consider all the indicators together as a set so that, firstly, its indicators do not represent identical and repeated effects; secondly, reflect all aspects of the underlying unsustainability problems identified in the previous step (i.e., Step 3).

Meanwhile, in the final selection of indicators, various studies were used, the most important of which were: Farshad and Zinck (2001) [19], Zinck et al. (2004) [20], Lopez-Ridaura et al. (2005) [21], Gomez-Limon and Sanchez-Fernandez (2010) [16], Vecchione (2010) [22], Pourzand and Bakhshoodeh (2014) [23], and Haileslassie et al. (2016) [8]. Also, the following review studies: Hayati et al. (2010) [18] Roy and Chan (2012) [15], and Van Pham and Smith (2014) [4] were applied in the present study. The latter was considered as the reference basis, especially for driver (potential) indicators. In addition, all selected indicators were confirmed by the selected members of all groups of stakeholders and experts.

Finally, nine status or actual sustainability indicators, and eight driver or potential sustainability indicators were obtained employing the above procedure.

\subsubsection{Status Indicators}

The triple sustainability goals, seven categories of unsustainability issues, and nine agricultural sustainability status indicators that are hierarchically related to each other, and the economic, social or environmental dimension of each indicator are shown in Table 2. Definition and nature of each of these indicators are as follows:

1. Farm income: Iranian Rials per farm are a measure of the income and profitability of agricultural activity of producers and the financial viability/survival of the farmer's household. It can also reflect the farmer's capacity to invest in the farm.

2. Insurance: The percentage of agricultural land under insurance is an indicator of minimizing the risk and income instability of farmers.

3. Food self-sufficiency: This is a measure of the food security of the agricultural household resulting from the production of adequate food by subsistence farming or the ability to buy food. The percentage of 0.5 hectares and larger farms was used as a proxy.

4. Discriminatory employment: The percentage of male and female farmer's wage differential is a form of gender inequality in agriculture in the community, which shows social justice and the distribution of people's income in the agriculture sector and its role in society. It can also indicate the trend of (positive or negative) changes in social justice among farmers and society over time.

5. Crop productivity: It is measured as the physical yield of the major $(\mathrm{kg} / \mathrm{ha})$ and represents the efficiency of land use, which can indicate changes in production system technology and sustainability of agricultural productivity over time.

6. Access to extension services: The number $(\mathrm{N})$ of agricultural extension and services' centers per ten thousand farms was used as a proxy for the level of access to extension services. This indicator 
is both a right and a kind of justice in the agricultural community, which is the basis for increasing knowledge, production and social-economic well-being that maintains and improves social justice in the society over time.

7. Groundwater depletion: This is measured through the total annual depletion of deep, semi-deep wells, qanats ("It is a method of tapping groundwater without the use of lifting devices. By sinking a line of wells and then linking them with a gently sloping tunnel, the groundwater is brought from the higher ground until, after sometimes tens of kilometres, it reaches the surface to create what is, in effect, an artificial oasis (Lambton 1953)" [9] (p. 1612)) (or chain wells and dikes) and springs per hectare of agricultural land $\left(\mathrm{m}^{3} / \mathrm{ha}\right)$, which is a measure of the depletion of groundwater in agricultural lands and lowered water tables. Changes in this indicator over time reflect the changes in water resource management and its effect on the ability to maintain welfare in the future.

8. Agrochemicals use: The amount of applied chemical fertilizers $(\mathrm{kg} / \mathrm{ha})$ in agricultural land, including total fertilizers nitrogen (urea + ammonium nitrate), phosphate (ammonium phosphate + triple superphosphate + superphosphate), and potassium (potassium sulfate + potassium chloride). This is a measure of the quantitative and qualitative degradation of agricultural land, due to the lack of protection in agricultural activity, which can also have adverse effects on the well-being of farmers and the society through pollution of the environment and products.

9. Biodiversity: Here, the crop diversity as a proxy for biodiversity, a measure of protecting the environment, and its agricultural ecosystem, is used as follows:

$$
H=-\sum_{i=1}^{i=s} P_{i} \log P_{i}
$$

where $H$ is the degree of crop diversity, $P_{i}$ is the proportion of total harvested area belonging to the $i$ th crop and $s$ is the number of crops [24].

Table 2. Indicators of agricultural sustainability status based on sustainability goals and problems in the three dimensions.

\begin{tabular}{|c|c|c|c|c|}
\hline Sustainability Goals & Sustainability Problems & Indicators & Unit & Dimension \\
\hline \multirow{2}{*}{$\begin{array}{l}\text { Increasing the well-being } \\
\text { (of farmers and society) } \\
\text { over time }\end{array}$} & \multirow{2}{*}{$\begin{array}{l}\text { Low and insufficient income of } \\
\text { farmers, and its instability }\end{array}$} & Insurance & $\%$ & Economic \\
\hline & & $\begin{array}{c}\text { Food } \\
\text { self-sufficiency }\end{array}$ & $\%$ & Social \\
\hline \multirow{2}{*}{$\begin{array}{l}\text { Improving production } \\
\text { processes and capacities } \\
\text { through time }\end{array}$} & $\begin{array}{l}\text { Low efficiency and productivity of } \\
\text { production processes }\end{array}$ & Crop productivity & $\mathrm{kg} / \mathrm{ha}$ & Economic \\
\hline & $\begin{array}{c}\text { Lack of access or inadequate access } \\
\text { of farmers to the required } \\
\text { knowledge and information }\end{array}$ & $\begin{array}{l}\text { Access to extension } \\
\text { services }\end{array}$ & value & Social \\
\hline \multirow{2}{*}{$\begin{array}{l}\text { Conserving the } \\
\text { environment over time }\end{array}$} & Soil loss and salinity & Agrochemicals use & $\mathrm{kg} / \mathrm{ha}$ & Environmental \\
\hline & $\begin{array}{c}\text { Reduced biodiversity caused by } \\
\text { lack of environmental protection } \\
\text { and drought }\end{array}$ & Biodiversity & value & Environmental \\
\hline
\end{tabular}

Source: The research findings. 


\subsubsection{Driver Indicators}

Table 3 shows the hierarchy of nine indicators of agricultural sustainability driver that are categorized as "demographic and natural", "socio-economic" and "political and institutional" classes (see Reference [4]), and explains them by defining each of the indicators.

Table 3. Indicators of agricultural sustainability drivers in the three classes: Definitions.

\begin{tabular}{|c|c|c|}
\hline Sustainability Classes & Sustainability Indicators & Definitions \\
\hline \multirow{3}{*}{ Demographic and natural } & Population growth & This was measured as $\%$ growth rate. \\
\hline & Farm size & It was measured by ha of agricultural land. \\
\hline & Urbanization & This indicator was calculated as \% of urban population. \\
\hline Socio-economic & $\begin{array}{l}\text { Technology availability and } \\
\text { application }\end{array}$ & $\begin{array}{l}\text { In the present study, the \% of the proportion of total cultivated } \\
\text { land area belonging to the agricultural land area with modern } \\
\text { irrigation technologies (including drip irrigation and/or rain } \\
\text { irrigation) was used as a proxy for access level or availability and } \\
\text { application of technology. }\end{array}$ \\
\hline \multirow[t]{2}{*}{ Political and institutional } & $\begin{array}{c}\text { Governance and } \\
\text { institutional capacities }\end{array}$ & $\begin{array}{l}\text { Here, the average of six indices of control of corruption, } \\
\text { government effectiveness, political stability and absence of } \\
\text { violence/terrorism, rule of law, regulatory quality, voice and } \\
\text { accountability-provided by the World Bank [25] *-were used as } \\
\text { proxy for the "governance and institutional capacities" (For more } \\
\text { information see: References [26-28]).* These indices are presented } \\
\text { internationally and at the national level, so we used them for } \\
\text { values that include no-dimensional scores of -2.5 to } 2.5 \text { for Iran } \\
\text { and their annual changes for the study counties. }\end{array}$ \\
\hline & $\begin{array}{l}\text { Producer organizations and } \\
\text { social capital as participation }\end{array}$ & $\begin{array}{l}\text { In the current study, this indicator was measured as the } \% \text { of } \\
\text { farmers participating in agricultural cooperatives. }\end{array}$ \\
\hline
\end{tabular}

Source: The research findings and based on Reference [4].

Significance of these indicators are as follows:

1. Population growth: A measure of increased pressure for access to arable lands and, subsequently reduced yields and resource degradation, due to limited access to the appropriate technologies and institutions required.

2. Farm size: Because small farms are often poor in terms of access to resources, and they are unable to invest in inputs of improving the soil fertility, productivity gradually decrease; therefore, the size of the farm can be a measure of access to resources in agriculture, greater productivity, and long-term profit.

3. Education level: Farmer's education has a positive effect on agricultural productivity [29], which can occur in a variety of ways, such as better access to information and possibly the earlier adoption of new technologies and hence, more efficient resource allocation [30,31]. Educated farmers are also more likely to conduct practices of improved soil fertility management [32] and environmentally sound management [33].

4. Urbanization: Urbanization can cause scarcity of agricultural land, shortage of agricultural labor and, consequently, reduction in production, and a threat to food security through competition for resources, such as land, labor and water.

5. Technology availability and application: In recent decades, applying appropriate technologies has been a driving force for improving water use efficiency, soil fertility, and pest management, and has, therefore, contributed to the improvement of crop productivity and sustainability [1,34]. 
In particular, the application of technologies that improve water use efficiency has both increased agricultural productivity and agricultural sustainability in developing countries [35,36].

6. Levels of poverty: Poverty is widely accepted as a driving force for the degradation of resources [37].

7. Governance and institutional capacities: "Governance is an essential driver of both agricultural productivity and sustainability in developing countries" [4] (p. 335). Moreover, "The capacity of institutions to provide public goods and services is critical for agricultural performance and sustainability" [4] (p. 335), as conventional institutional controls and practices play an important role in determining the final effectiveness of a specific set of agricultural policies or technological interventions [38,39].

8. Producer organizations and social capital as participation: "Producer organizations in small-scale agriculture play an important role in improving market access by reducing transaction costs, increasing bargaining power, fostering technology adoption through social learning and increasing participation in policy dialogue and decision-making" [4] (p. 335). Improving social capital via the creation of producer groups, ultimately, increases yields, labor wages, water use efficiency and equality and decreases use of agrochemicals [40].

\subsection{Step 5: Constructing Composite Indicators of Sustainability Status and Driver}

In the analysis of sustainability and related policies, it is necessary to interpret a variety of indicators. In order to facilitate this process and use the indicators as a decision support tool, they can be used "in the form of a composite index, whereby individual indicators scores are combined into a single number (Dantsis et al., 2010)" [8] (p. 713). In this case, general assessments of agricultural performance and comparisons of farms, systems, areas, etc. can be made. Some of the advantages and possible disadvantages of composite indicators were categorized in the study of Gomez-Limon and Sanchez-Fernandez (2010) [16]. In the present study, composite indicators that cover all the above-mentioned problems and dimensions of sustainability are constructed and presented to assess the sustainability status and drivers.

In the context of methodology, the related literature shows that there are many techniques for building sustainability indices. In this study, some of the guidelines for building composite indicators offered by Gomez-Limon and Sanchez-Fernandez (2010) [16] are used as follows:

1. Indicator selection and data collection. After selecting the indicators in the previous step (i.e., Step 4), collecting their data and calculating the numerical indicators is done at this stage.

2. Normalization of indicators. After calculating the indicators, their conversion to non-dimensional variables (normalization) is necessary before any aggregation, in order to allow them to be compared and to carry out arithmetical operations on them. For this purpose, there are various techniques [41]. In this study, the "min-max" normalization $[8,16]$ was used as follows (Equation (1)) to change the values of all normalized indicators within dimensionless interval $(0,1)$, where zero is the worst possible value of the indicator (i.e., the least sustainable or the most unsustainable) and 1 is the best (i.e., the most sustainable) one:

$$
x^{\prime}=\frac{x-\min (x)}{\max (x)-\min (x)},
$$

where, $x^{\prime}$ is the normalized value of observation $x$, and $\min (x)$ and $\max (x)$ are minimum (worst) and maximum (best) observations in the total sample, respectively [41].

3. Weighting indicators. The weighting step enables us to determine the relative importance of the individual base indicators. Weighting techniques for building indexes can be divided into "positive" or endogenous and "normative" or exogenous [42]. "The positive or endogenous techniques are those that allow us to obtain the weights of the base indicators via statistical procedures, without having to include value judgements of their relative importance. [...] 
Normative or exogenous techniques attempt to assign different weights to the indicators as a function of the opinion of experts and external decision-makers" [16] (pp. 1067-1068). In order to consider sustainability as a social construct, the normative techniques including Fuzzy Pairwise Comparisons (FPC) and Analytic Hierarchy Process (AHP) have been used in the present study to introduce social preferences into the model and analysis for assigning different weights to indicators, as a function of the views of external decision makers (the groups mentioned above in Step 3).

The fuzzy pairwise comparison method, introduced by Van Kooten et al. (1986) [43] as an alternative approach to assessing the hierarchy of goals among farmers, has been used by researchers, such as Boender et al. (1989) [44], Mendoza and Sprouse (1989) [45], Ells et al. (1997) [46], Basarir and Gillespie (2006) [47], and Berkhout et al. (2010) [48]. This method is similar to other pairwise comparison methods that ask the respondent to compare two options. But instead of being forced to make a binary choice between two options, the degree of preference (of one option over another) is extracted. The value of the scale of each option is based on the whole set of compared pairs (see References $[43,47]$ for more details on the FPC method). Compared to the AHP method that the respondent has to select one of the discrete preference degrees, the advantage of the FPC is that the degree of preference for an option over another option is chosen from among continuous degrees [47].

Considering the capabilities and advantages of the FPC method, this method was used to derive the relative importance of sustainability indicators. In this way, all possible combinations of these nine indicators were compared for each respondent by plotting a line of unit length between each indicator pair to represent relative preferences. The respondent was then asked to specify the preference for one over the other by putting a cross on the line. The cross in the middle of the line means the same relative importance of the two indices; however, if it is closer to each end, it indicates the greater preference of that indicator. The degree of preference of an indicator $\left(j\right.$ th) over another $(k \mathrm{th})$, which is represented by $R_{j k}$, is measured as 1 minus the distance from the cross to that indicator ( $j$ th) ( $j$ is not equal to $k$ ). Based on the fuzzy preference matrix of Van Kooten et al. (1986) [43], the preference or weight, $w$, of each $k$ th indicator is equal to:

$$
w_{k}=1-\left(\frac{\sum_{j=1}^{j=n} R_{j k}^{2}}{n-1}\right)^{\frac{1}{2}}
$$

where, $n$ is the number of status indicators equal to 9 , so $j$ and $k$ vary from 1 to 9 . The value of $w_{k}$ is in the range of 0 and 1 . The larger $w_{k}$, the more the importance of that indicator. In order to achieve the practical objectives of the study, including the determination of the economic, social and environmental sustainability status (i.e., the achievement of the relevant composite indicators), in addition to the main objective of agricultural sustainability (i.e., achieving the composite indicator of agricultural sustainability status), the FPC method is adapted. In this way, after deriving the weights of the base indicators, they were separately standardized (standardized weights should add up to one) for the construction of the composite indicators of each of the three dimensions and also for the construction of the overall sustainability composite indicator (Figure 3). 


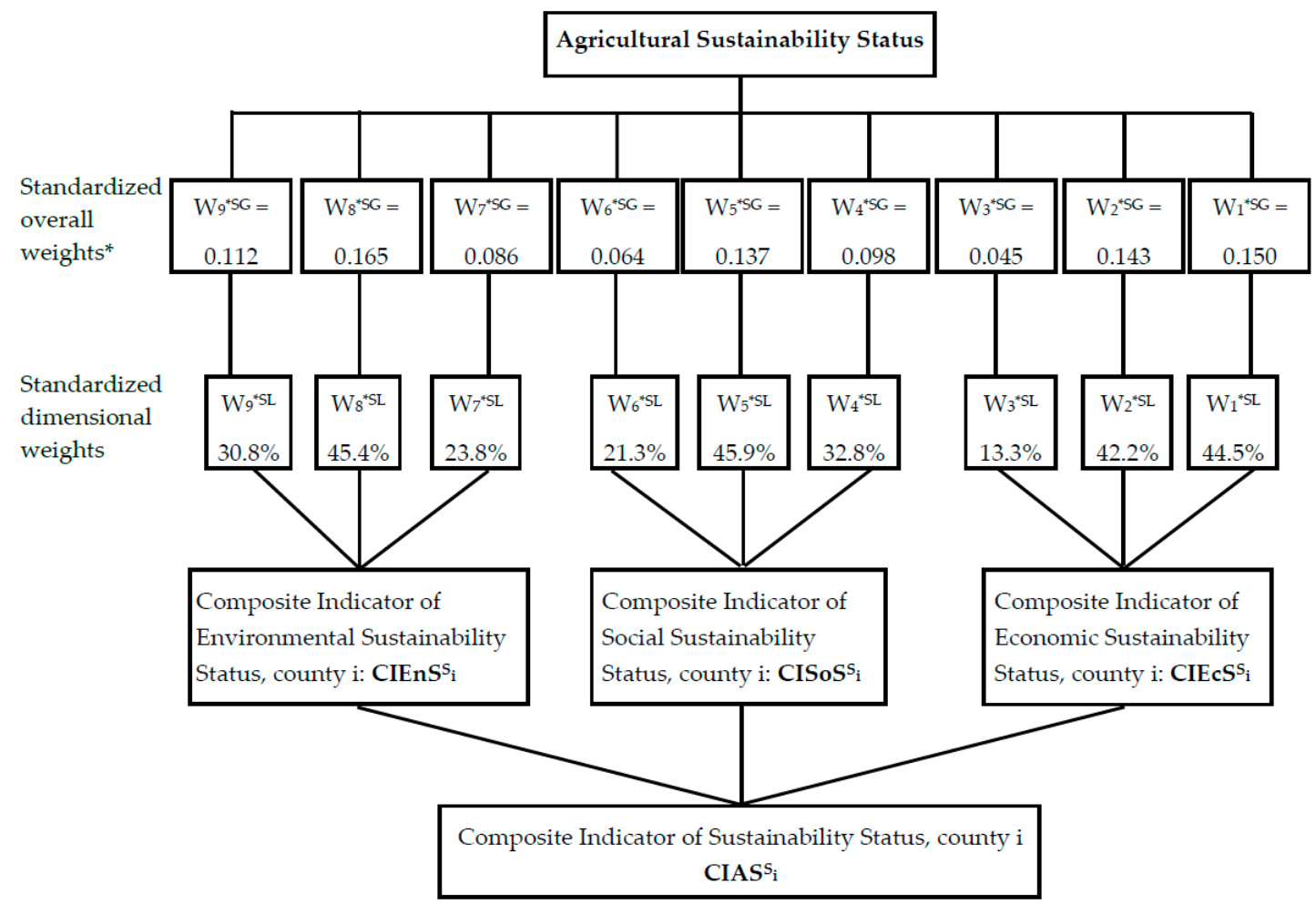

Figure 3. Hierarchical structure for constructing composite indicators of economic, social and environmental sustainability status, as well as the composite indicator of agricultural sustainability status, in terms of Fuzzy Pairwise Comparisons (FPC) technique. * The weights $w^{S}{ }_{k}$ are for sustainability indicators (Table 2), where $k$ is 1 to 9 , respectively, corresponding to indicators of crop productivity, farm income, insurance, food self-sufficiency, discriminatory employment, access to extension services, agrochemicals use, groundwater depletion, and biodiversity. Source: The research findings.

The AHP technique, created by Saaty $(1980,1990)[49,50]$ that has been widely used as a tool for complex decision makings [51], is a structural but flexible technique for multi-criteria decision making [52], which can be adapted to build composite indices [16] (see References [53,54]). In the present study, it has been used to weigh the sustainability driver indices in the composite indicator construction process.

The AHP approach is based on dealing with complex decision problems using its structure as a hierarchy of objective, criteria, and alternatives. Figure 4 shows the multi-level structure of sustainability driver indicators for this study. Relative importance or weight $\left(w_{k}\right)$ of the criteria or sub-criteria that are connected to each node is obtained through their pairwise comparisons according to the relevant criterion (which is connected to the previous node). According to the Saaty scale [49], the values used to perform these pairwise comparisons are in the range of 1-9. Based on the quantitative judgments given by these comparisons, the Saaty matrices are constructed to determine the vector of weights $\left(w_{1} \ldots \ldots w_{k} \ldots w_{n}\right)[52]$.

4. Aggregation of indicators. After normalizing and weighting the base indicators, there is a need for functional form for aggregating them into a single index or (unique) composite indicator. In the present study, the "Weighted Sum of Indicators" (WSI) was used to construct the Composite Indicators of Economic Sustainability Status $\left(\mathrm{CIEcS}^{\mathrm{S}}\right)$, Social $\left(\mathrm{CISoS}^{\mathrm{S}}\right)$, Environmental $\left(\mathrm{CIEnS}^{\mathrm{S}}\right)$ and overall Agricultural Sustainability Status $\left(\mathrm{CIAS}^{\mathrm{S}}\right)$, as well as to build the Composite Indicators 
of Agricultural Sustainability Driver (CIAS ${ }^{\mathrm{D}}$ ). Mathematically, WSI is a linear aggregation method that is used for a set of normalized indicators [with standardized weights] [16]:

$$
C I=\sum_{k=1}^{k=n} w_{k}^{*} \cdot I_{k}
$$

where $C I$ is the agricultural sustainability composite indicator derived from a set of $n$ indicators; $I_{k}$ is the normalized value of indicator $k$; and $w_{k}^{*}$ is the standardized weight of indicator $k$, which is calculated from the following equation:

$$
w_{k}^{*}=\frac{w_{k}}{\sum_{k=1}^{n} w_{k}}
$$

where, $w_{k}$ is the unstandardized weight of indicator $k$. Accordingly, the composite indicators constructed in this study will be:

$$
\begin{aligned}
& \text { CIEcS } S^{S}=\sum_{k=1}^{k=3} w_{k}^{* S L} \cdot I_{k}^{S}, \\
& \text { CISoS }^{S}=\sum_{k=4}^{k=6} w_{k}^{* S L} \cdot I_{k}^{S}, \\
& \text { CIEnS } S^{S}=\sum_{k=7}^{k=9} w_{k}^{* S L} \cdot I_{k}^{S}, \\
& \text { CIAS }^{S}=\sum_{k=1}^{k=9} w_{k}^{* S G} \cdot I_{k}^{S}, \\
& \text { CIAS }^{D}=\sum_{k=1}^{k=8} w_{k}^{* D} \cdot I_{k}^{D},
\end{aligned}
$$

where, the superscripts $S, L, G$, and $D$ refer to Status, Local (i.e., dimensional), Global or overall (i.e., all three dimensions together) and Driver, respectively.

In order to make comparisons based on the results of the composite indicators obtained, the study counties were categorized into classes of relative sustainability levels for economic, social and environmental dimensions, and the overall agricultural sustainability status, and also for agricultural sustainability drivers. For this purpose, the Interval of Standard Deviation from the Mean (ISDM) was applied to achieve the four-level distribution of the counties as follows [55]:

(A) Weak: Unsustainable $A<$ Mean $-S D$

(B) Moderate: Relatively unsustainable Mean $-S D \leq B \leq$ Mean

(C) Good: Relatively sustainable Mean $<C \leq$ Mean $+S D$

(D) Great: Sustainable Mean $+S D<D$

The Steps 6, 7 and 8 of the methodology (Figure 2) include: "Step 6. Providing results through tables, charts and sustainability maps"; "Step 7. Different comparisons and analyses based on the results and objectives of the study"; and "Step 8. The final conclusions and interpretations, suggestions and, if possible, policy recommendations"; corresponds to the following sections, including results, discussion, and conclusions, respectively. 

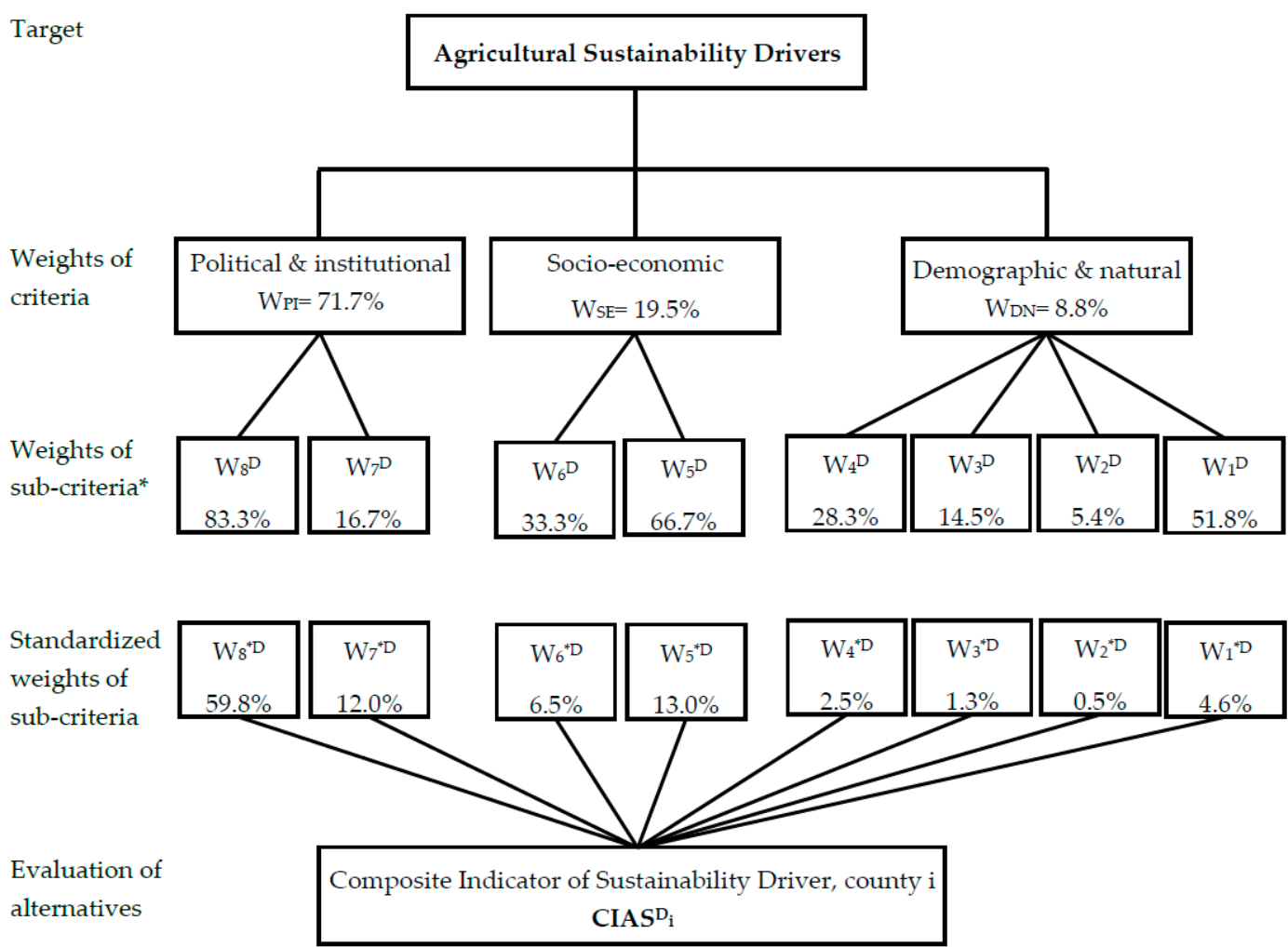

Figure 4. Hierarchical structure for constructing the composite indicator of agricultural sustainability driver, in terms of Analytic Hierarchy Process (AHP) technique. ${ }^{*}$ The weights $w^{D}$ are for sustainability indicators (Table 3), where $k$ is 1 to 8 , respectively, correspondedcorresponding to indicators of population growth, farm size, education level, urbanization, technology availability and application, levels of poverty, governance and institutional capacities, and producer organizations and social capital as participation. Source: The research findings.

\subsection{Data Sources}

The empirical estimations of this study were based on two major sources of data and information: (1) Data and information collected from the Statistical Center of Iran. This information was used to calculate the base indicators. The main sources in this category included the "Public Agricultural Census" of 2003 and 2014, and the "Statistical Yearbook" of 2003 and 2015 in Kerman province, which provided the statistical basis for most of the indicators. Data related to the study area were also extracted from items, such as the "Sale Price of Agricultural Products and Costs of Agricultural Services in Rural Areas of the Country" and "Raw Data of Household Costs and Income of the Country" for the years 2003 and 2015, and the "National Population and Housing Census" of Iran in 2016. Some reasons for selecting and using this category of data sources are explained in Section 3.2, and (2) the data and information obtained from face-to-face interviews and questionnaires. In order to identify agricultural sustainability issues, interviews were conducted with selected stakeholders and experts (described in detail in Section 3.3) in the study area. Also, in order to find out the relative importance of indicators in the process of building composite indicators, a questionnaire was designed based on available theories (see Section 3.5 for details of weighting methods used in this study, including FPC and AHP) and completed by the same interviewed groups. All of the above stages were carried out in summer 2017 in Kerman county. 


\section{Results (Step 6. Providing Results through Tables, Charts and Sustainability Maps)}

Following the previous five steps, the indices for the counties under study were obtained for years 2003 and 2015. In this step (i.e., Step 6), tables, figures and diagrams have been designed and presented that, while being brief, facilitate the analyses and comparisons required (Step 7). For this purpose, the composite indicators of economic, social and environmental sustainability status, $\mathrm{CIECS}^{\mathrm{S}}, \mathrm{CISOS}^{\mathrm{S}}$ and CIEnS $^{S}$, respectively, as well as the composite indicators of (overall) agricultural sustainability status $\left(\mathrm{CIAS}^{\mathrm{S}}\right)$ for the counties are presented in Table 4.

Table 4. Composite indices of Agricultural Sustainability Status.

\begin{tabular}{ccccccccc}
\hline \multirow{2}{*}{ County } & \multicolumn{2}{c}{ CIEcS $^{\text {S }}$} & \multicolumn{2}{c}{ CISoS $^{\text {S }}$} & \multicolumn{2}{c}{ CIEnS $^{\text {S }}$} & \multicolumn{2}{c}{ CIAS $^{\text {S }}$} \\
\cline { 2 - 10 } & $\mathbf{2 0 1 5}$ & $\mathbf{2 0 0 3}$ & $\mathbf{2 0 1 5}$ & $\mathbf{2 0 0 3}$ & $\mathbf{2 0 1 5}$ & $\mathbf{2 0 0 3}$ & $\mathbf{2 0 1 5}$ & $\mathbf{2 0 0 3}$ \\
\hline Bardsir & 0.462 & 0.413 & 0.959 & 0.423 & 0.893 & 0.641 & 0.762 & 0.499 \\
\hline Ravar & 0.377 & 0.277 & 0.893 & 0.177 & 0.944 & 0.428 & 0.737 & 0.302 \\
\hline $\begin{array}{c}\text { Rafsanjan and Anar } \\
\text { Zarand and } \\
\text { Kuhbanan }\end{array}$ & 0.335 & 0.296 & 0.53 & 0 & 0.833 & 0.647 & 0.575 & 0.335 \\
\hline Sirjan & 0.276 & 0.292 & 0.592 & 0.046 & 0.883 & 0.333 & 0.591 & 0.233 \\
\hline Shahr-e-Babak & 0.33 & 0.818 & 0.67 & 0.147 & 0.786 & 0.601 & 0.597 & 0.539 \\
\hline Kerman & 0.507 & 0.529 & 0.743 & 0.172 & 0.802 & 0.849 & 0.685 & 0.539 \\
\hline Mean & 0.379 & 0.445 & 0.715 & 0.181 & 0.85 & 0.608 & 0.65 & 0.425 \\
\cline { 2 - 9 } & 0.412 & 0.618 & 0.304 & 0.81 & 0.756 & 0.603 & 0.53 \\
\hline
\end{tabular}

Source: The research findings.

Table 5 shows the results of the composite indicators of agricultural sustainability driver (CIAS ${ }^{\mathrm{D}}$ ) calculated for the desired years and counties under study.

Table 5. Composite indices of Agricultural Sustainability Drivers (CIAS ${ }^{\mathrm{D}}$ ).

\begin{tabular}{cccccccc}
\hline Year & Bardsir & Ravar & $\begin{array}{c}\text { Rafsanjan } \\
\text { and Anar }\end{array}$ & $\begin{array}{c}\text { Zarand and } \\
\text { Kuhbanan }\end{array}$ & Sirjan & Shahr-e-BabakKerman \\
\hline 2003 & 0.482 & 0.29 & 0.576 & 0.215 & 0.802 & 0.735 & 0.823 \\
\hline 2015 & 0.457 & 0.215 & 0.137 & 0.517 & 0.506 & 0.345 & 0.5 \\
\hline \multicolumn{7}{c}{ Source: The research findings. }
\end{tabular}

The AMOEBA (Dutch acronym for a general method of ecosystem description and assessment) models (see References [56,57]) were applied to help analyze and compare (the composite indicators of) the three dimensions of agricultural sustainability status with each other in one year, relative to another year, and of course all of them for the study counties, relative to each other (Figure 5). 


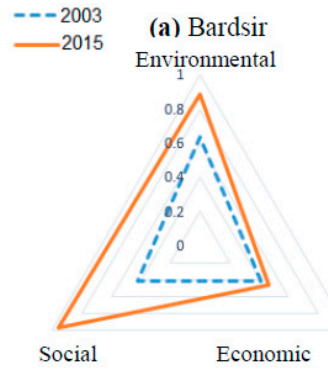

(e) Sirjan Environmental

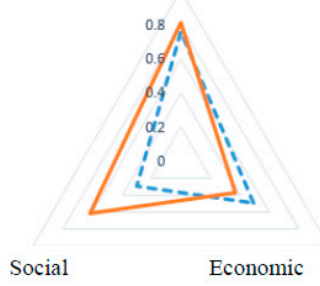

(b) Ravar Environmental

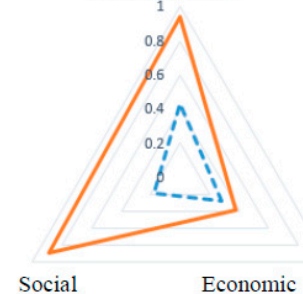

(f) Shahr-e-Babak Environmental

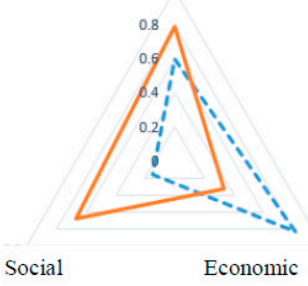

(c) Rafsanjan \& Anar Environmental

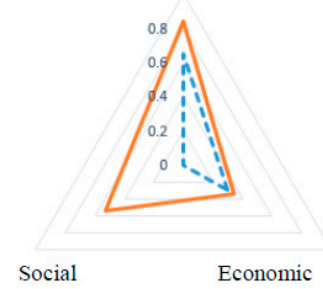

(g) Kerman Environmental

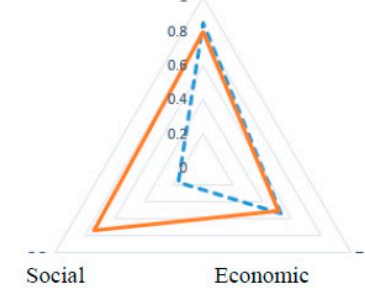

(d) Zarand \& Kuhbanan Environmental

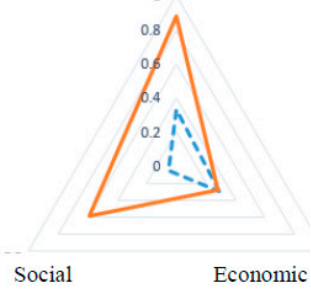

Social Economic

Figure 5. AMOEBA diagrams of agricultural sustainability dimensions in the study counties of Kerman province, Iran over time. Source: The research findings.

Also, the results of classification of the study counties across the relative sustainability classes can be shown as sustainability maps as presented in Figure 6a-e.

Agricultural sustainability assessment outputs can also be presented in graphical form using scales of sustainability levels. Figure 7, which is a modified "Barometer of Sustainability" (see Reference [58-60]), shows the Barometer of Agricultural Sustainability (BAS) that was introduced and applied in this study as a tool for explaining the comprehensive level of sustainability or the level of joint sustainability (status and drivers for sustainability or actual and potential sustainability, respectively). In this figure, the four-level classification of the comprehensive sustainability was performed based on the values of (composite indicators) CIAS $^{S}$ and CIAS $^{\mathrm{D}}$ (presented in Tables 4 and 5, respectively) and the ISDM classification (see Section 3) as follows:

$\mathrm{I}=$ sustainable: If the values of both $\mathrm{CIAS}^{\mathrm{S}}$ and $\mathrm{CIAS}^{\mathrm{D}}$ are in category D;

$\mathrm{II}=$ relatively sustainable: If one is in category $\mathrm{C}$ and the other is in category $\mathrm{C}$ or $\mathrm{D}$;

$\mathrm{III}=$ relatively unsustainable: If one is in category $\mathrm{B}$ and the other is in category $\mathrm{B}$ or $\mathrm{C}$ or D;

IIII = unsustainable: If at least one is in category A. 


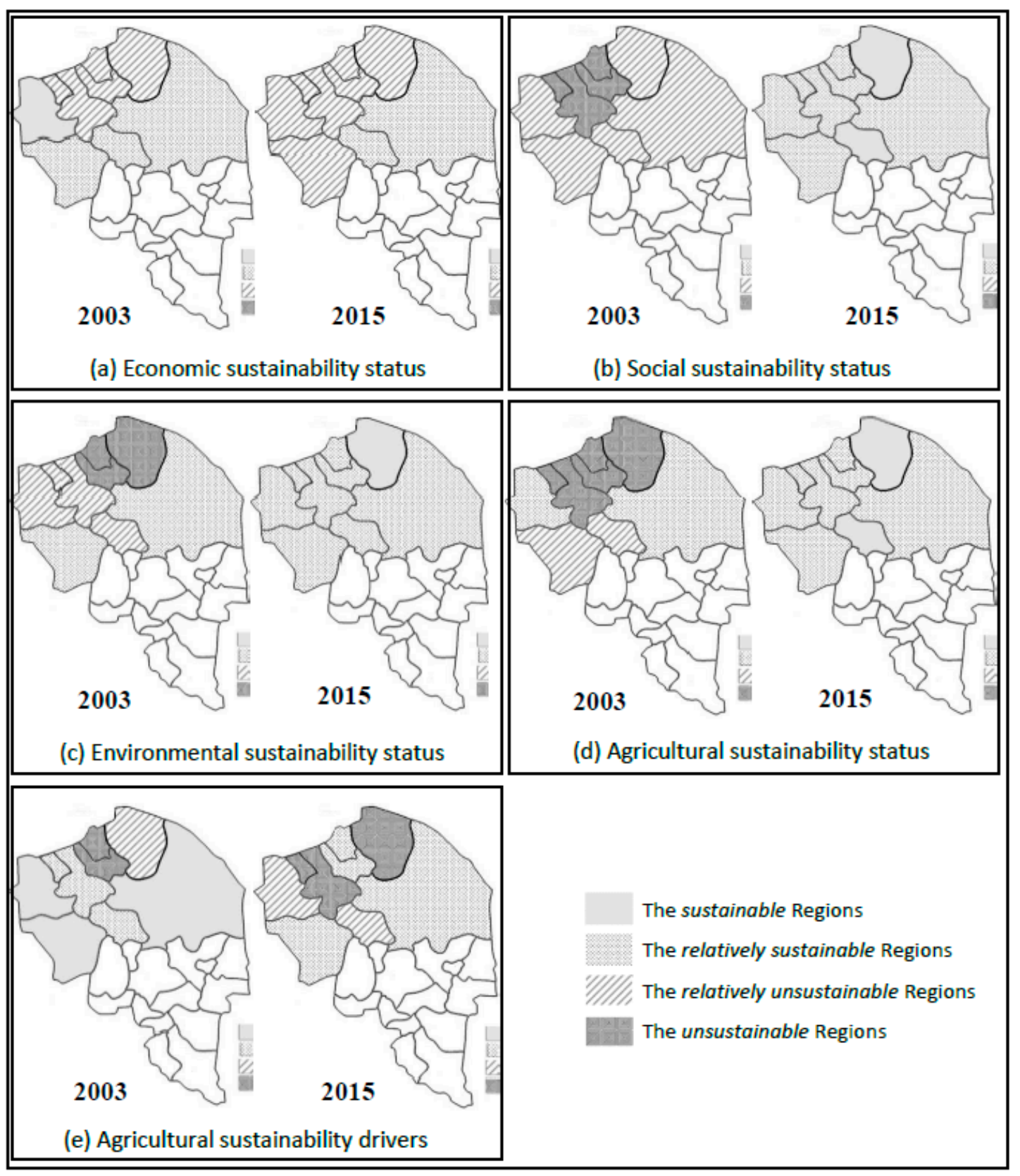

Figure 6. Agricultural Sustainability Maps in Kerman province, Iran. Source: The research findings. 


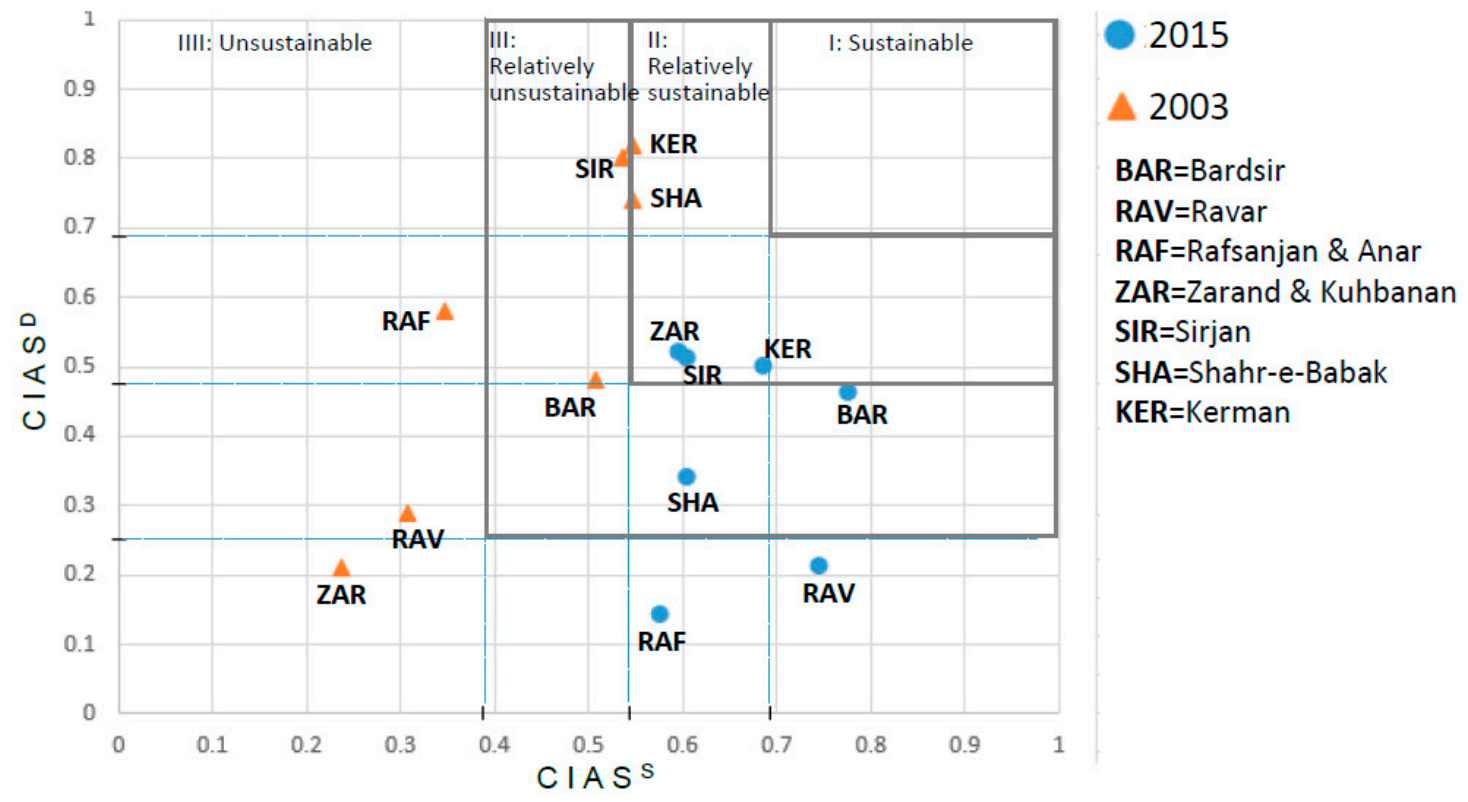

Figure 7. Comprehensive Levels of Agricultural Sustainability: Agricultural sustainability status and drivers jointly in the study counties of Kerman province, Iran, over time. Source: Authors' own elaboration and the research findings.

\section{Discussion (Step 7. Different Comparisons and Analyses Based on the Results and Objectives of the Study)}

A general objective of the present study has been objectivization of the concept of agricultural sustainability by introducing and applying a practical method for assessing agricultural sustainability in the counties of Bardsir, Ravar, Rafsanjan, Anar, Zarand, Kuhbnan, Sirjan, Shahr-e-Babak and Kerman in Kerman province, Iran. The results of this assessment were presented in the tables and figures of the previous section.

As shown in Tables 4 and 5, the obtained values of the status and driver composite indicators vary depending on the county and the year under review. Therefore, a variety of comparisons can be made:

1. Comparison of the three dimensions of agricultural sustainability for the whole set of counties: In Table 4, the last picture of the three dimensions of sustainability status in the study counties of Kerman province (2015) indicates that the economic dimension has the least amount. This is while the social dimension (with a significant improvement compared to 2003) is slightly less than two times more than the economic dimension. In addition, the environmental dimension is more than two times better. Moreover, in comparing the trend of sustainability, it can be said that social and environmental sustainability have been improved, while economic sustainability has decreased.

2. Analysis of the sustainability status of the three dimensions (economic, social and environmental), and the overall sustainability status and drivers, as well as the comprehensive levels of agricultural sustainability of each county per year:

This can be done by direct comparison of each indicator with its maximum value (i.e., 1). Of course, in order to easily observe and understand the results of this type of comparisons, the composite indicators were classified into the quadruple categories of unsustainable, relatively unsustainable, relatively sustainable and sustainable, and the results are visually presented through "Sustainability Maps" of (the study regions in) Kerman province in Figure 6. As shown in this figure, for example, Kerman county in terms of agriculture has a relatively sustainable economic and environmental status in 2003, and relatively unsustainable social status. The (overall) agricultural sustainability status in this county is relatively sustainable 
and is considered to be sustainable in terms of agricultural sustainability drivers. Based on the sustainability status of the three dimensions, the overall sustainability status and sustainability drivers, the county was found to be relatively sustainable in 2015 . The comprehensive agricultural sustainability levels of each county, which classify the sustainability status and drivers together in the form of four levels of sustainability, were defined. This item can be seen in Figure 7 without making a global composite index. With the help of this figure, it can easily be seen that, for example, Zarand and Kuhbanan are in the "unsustainable" class in 2003 and the comprehensive level of agricultural sustainability in Kerman county corresponds to the "relatively sustainable" class in both periods (2003 and 2015).

3. Review, comparison and analysis of agricultural sustainability status of each county in each of the three dimensions of economic, social and environmental, also its overall status and its drivers, as well as the comprehensive levels of agricultural sustainability over the years (2003 and 2015) means the analysis of the trend of sustainability change:

The sustainability maps of Figure 6, which are based on the ISDM classification of composite indices, make this comparison easy. For example, in map (d) of this figure, it can be seen that the agricultural sustainability status of the counties of Bardsir, Ravar, Rafsanjan and Anar, Zarand and Kuhbanan, Sirjan, Shahr-e-Babak and Kerman in 2003 is relatively unsustainable, unsustainable, unsustainable, unsustainable, relatively unsustainable, relatively sustainable and relatively sustainable, respectively, which has been promoted to the "sustainable" for the first two counties (i.e., Bardsir and Ravar) and improved to the "relatively sustainable" for the other counties in 2015. Therefore, it can be easily understood that the agricultural sustainability status has been improved in all of the study counties of Kerman province.

The possibility of this kind of comparison and analysis, especially for triple dimensions without using their overall composite indicator through the AMOEBA diagrams, is provided in Figure 5. In part (a) of this figure, it is observed that the agricultural sustainability status of Bardsir county has improved for all three economic, social and environmental dimensions in 2015, in comparison to 2003 (since the triangle with the full line of 2015 has completely covered the triangle with dotted lines in 2003), although the improvement in the social dimension is the highest and is the least in the economic dimension.

In the particular case of the overall sustainability status and the sustainability drivers jointly, Figure 7 can be very helpful. From the Barometer of Agricultural Sustainability, the comprehensive levels of agricultural sustainability status and drivers for each of the counties in 2003, including one of the four levels of I: Sustainable; II: Relatively sustainable; III: Relatively unsustainable; and IIII: Unsustainable, will be compared in 2003 with 2015. Accordingly, the comprehensive level of agricultural sustainability of "Zarand and Kuhbanan" has been improved from unsustainable to relatively sustainable in 2015 and Sirjan from relatively unsustainable in 2003 to relatively sustainable in 2015 (i.e., sustainability improvement trend). The counties of Ravar and "Rafsanjan and Anar" in the unsustainable class, Bardsir county in the relatively unsustainable class, and Kerman in the relatively sustainable class have a relatively constant comprehensive level of agricultural sustainability. Shahr-e-Babak, with its downward trend, fell from a relatively sustainable class in 2003 to a relatively unsustainable in 2015.

4. Comparison of different counties in each period (year) in each of the three dimensions and the overall status and drivers of sustainability, as well as the comprehensive levels of agricultural sustainability, and, finally, ranking or classification of their sustainability levels:

This type of county comparison can be done in direct priority based on the results of the two tables (Tables 4 and 5). For example, according to the CIAS ${ }^{S}$ in the last column of Table 4, Bardsir county (with 0.767) ranked first in 2015, followed by Ravar (0.737), and Kerman (0.685). The following ranking was Sirjan (0.603), Shahr-e-Babak (0.597), Zarand and Kuhbanan (0.591), and finally Rafsanjan and Anar (0.575), respectively. 
The composite indicators of CIAS $^{\mathrm{D}}$ in Table 5 show that Zarand and Kuhbanan (with a value of 0.517) had the highest potential agricultural sustainability level (or agricultural sustainability drivers) in 2015. The counties of Sirjan (0.506) and Kerman (0.500) ranked second and third, respectively. Bardsir (0.457), Shahr-e-Babak (0.345) and Ravar (0.245) ranked next. Finally, Rafsanjan and Anar (0.137) had the lowest potential sustainability level.

Another tool for this kind of comparison and analysis is the output of the ISDM classification, which is shown in Figure 6 as sustainability maps in this study. This figure consists of five parts, from (a) to (e), corresponding to the five composite indicators of the present study that cover the study counties. Each part consists of two sustainability maps, corresponding to the two years examined (2003 and 2015). The counties have been categorized across different sustainability classes, and in each map, the sustainability level of each county is specified in that year. For example, in Figure 6d, the map of 2015, it can be easily seen that Bardsir and Ravar counties are sustainable, and the other counties (Rafsanjan and Anar, Zarand and Kuhbanan, Sirjan, Shahr-e-Babak and Kerman) are relatively sustainable in terms of agricultural sustainability status.

Of course, the Barometer of Agricultural Sustainability (BAS) of Figure 7 can be also used to extract the comprehensive levels of sustainability of the counties in each of the years as well as the years in total, and compare them with each other. As shown in this figure, the comprehensive level of agricultural sustainability for none of the counties is sustainable. In 2015, Zarand and Kuhbanan, Sirjan and Kerman had the highest comprehensive levels of agricultural sustainability in the category "II: Relatively sustainable". Bardsir and Shahr-e-Babak were in the category "III: Relatively unsustainable", and Ravar and Rafsanjan, with the category "IIII: Unsustainable", had the lowest comprehensive level of agricultural sustainability. Although in 2003, Kerman and Shahr-e-Babak were relatively sustainable, Sirjan and Bardsir were placed in the "relatively unsustainable" category, and "Rafsanjan and Anar", Ravar and "Zarand and Kuhbanan" were in the "unsustainable" category.

\section{Conclusions (Step 8. The Final Conclusions and Interpretations, Suggestions and, If Possible, Policy Recommendations)}

In order to objectivize agricultural sustainability, the present study introduced a new framework including a set of step-by-step procedures as a fully practical model through its empirical application in the process of agricultural sustainability assessment in Kerman province, Iran. The conclusions can be drawn on two subjects: First, the conclusions of the application of this framework in Kerman province, Iran; and, secondly, the conclusions on the goodness or effectiveness evaluation of the proposed framework. These conclusions are presented in this section.

Contribution to the creation of an effective way to operationalize the concept of agricultural sustainability is valuable [61]. But this is an empirical application of innovative methods that, in the first place, helps to understand and learn the concept of sustainability, and then, on the one hand, makes use of results as the plans and policies, and, on the other hand, contributes to the development and improvement of sustainability assessment methods and processes.

The results of the application of the proposed framework for assessing agricultural sustainability in Kerman province, Iran, can be summarized as follows:

1. Agricultural sustainability levels vary in different regions and counties of Kerman province, and these levels also vary in different periods. However, the focus of this study was on the neighboring counties in the north of Kerman province with some common basic features-the dominant agricultural system is smallholding, the majority of them (five out of seven counties in 2003, equivalent to seven out of nine in 2015) had a major product of pistachios with more than $65 \%$ of the total area under cultivation and the main crop production of all dedicated to wheat. 
2. Based on the average values of the composite indicators of the three dimensions of the sustainability status of the counties in the years under study, the economic dimension had the lowest level of agricultural sustainability and the environmental dimension had the highest level.

3. According to the definition of Comprehensive Levels of Agricultural Sustainability (Section 4), which represent the quadruple categories of sustainability status and drivers jointly: Three counties (Zarand i.e., 'Zarand and Kuhbanan', Ravar and Rafsanjan i.e., 'Rafsanjan and Anar') out of all seven counties studied in Kerman province were placed in the lowest class, unsustainable, in 2003. Sirjan and Bardsir were classified in the relatively unsustainable category and only two counties (Kerman and Shahr-e-Babak) were classified as relatively sustainable. While in 2015, two counties (Ravar and Rafsanjan i.e., 'Rafsanjan and Anar') were unsustainable, two counties (Shahr-e-Babak and Bardsir) were relatively unsustainable, and three counties (Zarand i.e., 'Zarand and Kuhbanan', Sirjan and Kerman) were classified as relatively sustainable. In sum, although the trend of changes in the comprehensive levels of agricultural sustainability is evaluated positively, more than half of the counties are still unsustainable or relatively unsustainable in 2015, and none have been entered into the category "I: Sustainable".

It can be pointed out that first, there are many innovative aspects in this framework, including:

- Effective application of the element of time, both in the definition of sustainability, in its dynamic modeling, and in the analysis of the results of sustainable -and unsustainable- trends of real agricultural issues;

- Purposeful selection of "Region: County" scale in a case study to show the power of the model and -carefully- selected and designed indicators, so that it can obtain results and reports for the larger scale of the "county/region", as the political borders of the country, using the data collected directly from the smaller scale, i.e., every single agricultural holding through periodic censuses. In practice, this can be very important in state policy and planning, given the allocation of regional budgets, including political geographic boundaries;

- Introducing a coherent set of indicators that, on the one hand, can be mainly applied at different levels and multiple scales, and on the other hand, can reflect changes over time. Based on direct attention to the core problems of sustainability (i.e., agricultural unsustainability problems), these indicators can incorporate the sustainability status and drivers (or results and roots) of different dimensions (economic, social and environmental) and categories (demographic and natural, socio-economic, and political and institutional) into the process of modeling, indicator construction and final analyses;

- Applying different methods and techniques, especially to incorporate the concept of social constructs into the modeling process, and show their usefulness and compatibility with the proposed framework, such as FPC and AHP techniques; and,

- Providing a variety of analytical and visual tools, such as three dimensional composite indicators, overall indicators of agricultural status and driver, and especially sustainability maps and barometer of agricultural sustainability that are consistent with the proposed framework.

Second, applying the set of these innovations as the application of the proposed framework reveals the weaknesses and strengths of agricultural sustainability and agricultural holdings of each county, which can be reviewed and rooted in several levels:

- Comprehensive level of agricultural sustainability (status and driver jointly or both actual and potential);

- Level of overall agricultural sustainability status and/or drivers (i.e., overall actual and overall potential);

- Level of agricultural sustainability dimensions and/or classes (e.g., economic, social and environmental); 
- Level of base indicators, both for actual sustainability (status: Nine indicators) and potential (drivers: Eight indicators).

This multi-level separation, which has been possible through the use of the proposed base and composite indicators, is both important in terms of generalization and the extension of the concept of agricultural sustainability in society and among people, and in terms of understanding and solving the problem (sustainability problems) through operationalizing the complex concept of agricultural sustainability. By providing these capabilities, the framework can be a useful tool for public decision-makers in designing and implementing more sustainable agricultural policies over time.

Some of the most important criteria for assessing the effectiveness of the holistic methods for Agricultural Sustainability Assessment (ASA) (see Reference [5]) and evaluating our proposed framework based on them are:

(a) Scientific soundness: "Sustainability concept" is well-defined in our proposed framework (so that although it is a principles-based approach, it is also compatible with the Triple Bottom Line approach); "Methodological paradigms for the development of indicators" in our framework are both top-down (expert-led) and bottom-up (community/stakeholders-based); "Justification of indicator selection" is documented, as the logic of selecting the indicators and their relation to the agricultural sustainability are clearly described; "Data sources for indicators" in the proposed framework can include both primary and secondary data sources; "Use of qualitative and quantitative data to develop indicators" is possible within this framework; "Ability to consider sustainability issues across scales" is one of the main features of the framework. As can be seen in the suggested set of indicators, the method basically integrates and uses information on the sustainability issues of different scales over time; "Validation of indicators" was carried out through consultation and evaluation of experts and stakeholders (experts and farmers), and based on their comparisons; "Reference values for indicators" were relative ones in our case study, although in this framework, absolute reference values can also be used; "Data normalization" was performed for the base indicators by min-max normalization method; "Data aggregation" is used to construct a variety of composite indicators of the method as shown; "Sensitivity analysis", although not done in this study, but in the proposed framework, can be done using different methods, such as econometrics and regression techniques; and, "Spatial applicability" of the introduced framework, in our case study, is its application at the regional level. However, according to its perspective, objectives and practical measures for its implementation, especially the criteria for selecting the indicators described above, it can be applied across farm, local, regional and national scales.

(b) User-friendliness: "Learning dimension" of the proposed framework is realized through the empirical process of its implementation, since the application of an agricultural sustainability evaluation approach is itself a learning experience [62]; "Presentation of results" through numerical and graphical tables and figures is described in Step 6 of the framework, as shown in the results section; Being "available as software with video tutorials and with free access", having "guidelines" and being used as part of a formal "certification procedure or advisory tool" have not yet been met, because the method was proposed for the first time in the current study. Of course, software development and free access, as well as providing instructions are possible. At the same time, the calculations for counties and regions based on the proposed framework can be documented and included as part of their advisory reports, in support of agricultural policy planning and decision making aimed at improving the governance of this sector.

Accordingly, and based on the information in Table 1 in the introduction section, the framework introduced in this study (PSDCIFASA): (a) Like RISE, SAFE, IDEA, MOTIFS, SEAMLESS, MESMIS, and SAFA, provides the results both numerically and graphically. In addition, by introducing new concepts and tools, such as Barometer of Agricultural Sustainability (BAS) and Comprehensive Levels of Agricultural Sustainability based on some kind of visual aggregation of the composite 
indicators of sustainability status and driver, the PSDCIFASA framework emphasizes the visual aspect of providing key results and their easy comprehension. This can contribute to the framework's applicability; (b) in contrast to methods like RISE, IDEA, MOTIFS and MESMIS, has the advantage that through its multi-dimensional, multi-level and multi-scale structure, while providing a clear logical path and, in terms of social construct, flexible one for developing indicators, also considers and integrates information related to sustainability issues across scales (like SAFE, SEAMLESS, and SAFA); (c) compared to the SAFE and SEAMLESS methods, has the advantage that for the concept and definition of sustainability, it does not limit itself to the triple (economic, social, and environmental) dimension of the TBL approach and can use a principles-based approach; and (d) like SEAMLESS and SAFA, has a strong methodological approach for developing indicators based on both top-down (experts) and bottom-up (stakeholders) approaches. However, in comparison with them (and other methods mentioned above), it has the advantage of aggregating data as various composite indicators (status and driver) at different levels (dimensions, classes, and overall). Of course, SAFE and IDEA also offers the ability to aggregate at different levels, including three dimensions/scales and overall.

Therefore, since the framework presented in this study for assessing agricultural sustainability satisfies most of the criteria in a desirable manner, it can be concluded that it provides an effective assessment of agricultural sustainability and is a good tool for the evaluation. However, it is still new, and its potential needs to be reviewed and verified through more applied studies on different agricultural scales, levels and systems.

Finally, it should be noted that some limitations can affect the methodology used in this research, which is referred to as the three most important ones. The first category relates to those potential features of the proposed framework that were not investigated and tested in this study, such as sensitivity analysis. Because "sensitivity and uncertainty analysis play a fundamental role in increasing the quality and robustness of the answer provided by a sustainability assessment" [5] (p. 159). Therefore, it is necessary that this category of limitations be evaluated and addressed in the subsequent studies. The second category relates to data sources (quality and quantity). In the present research, the major need for extensive data was provided through formal statistical sources without spending too much. But, despite the fact that more complete data provides a stronger scientific support for the results, in order for the dynamic and universal applicability of the framework, it is necessary to look at the provision of data as a constraint and to address it. Therefore, it seems that global and governmental plans and actions are needed for establishing databases at different levels in countries so that the data required can be accurately and reliably collected over time (for example, years). The last category of limitations is related to the concept of social construct and the introduction of community preferences in different stages of the process of sustainability assessment. In the literature, especially in recent studies, the emphasis has been on the consideration of the views of various stakeholder groups and experts in the assessment process. But there are some limitations. It can be very important in practice through what methods and techniques and how it is done. Transparent and effective processes are needed to avoid distorted results. For example, the approaches and/or techniques used for interviewing, weighting indicators, etc. should be transparent. Although the present study has tried to some extent overcome these limitations in various ways (described in detail in the previous sections), further studies are needed.

Author Contributions: This research was part of a Ph.D. dissertation of the first author. The writing of this paper was led by S.F.-A. with substantial content guidance from H.M.B. as the supervisor, and, M.R.Z.M. and D.H. as advisors.

Funding: This research received no external funding.

Conflicts of Interest: The authors declare no conflict of interest. 


\section{References}

1. World Bank. Agriculture for Development: World Development Report 2008; World Bank: Washington, DC, USA, 2007.

2. Ligon, E.; Sadoulet, E. Estimating the Effects of Aggregate Agricultural Growth on the Distribution of Expenditures (English); World Bank: Washington, DC, USA, 2007.

3. Christiaensen, L.; Demery, L.; Kuhl, J. The (evolving) role of agriculture in poverty reduction-An empirical perspective. J. Dev. Econ. 2011, 96, 239-254. [CrossRef]

4. Van Pham, L.; Smith, C. Drivers of agricultural sustainability in developing countries: A review. Environ. Dev. Sustain. 2014, 34, 326-341.

5. Talukder, B.; Blay-Palmer, A. Comparison of methods to assess agricultural sustainability. In Sustainable Agriculture Reviews; Lichtfouse, E., Ed.; Springer: Cham, Switzerland, 2017; Volume 25, pp. 149-168, ISBN 2210-4410.

6. Pearson, C.J. Planning for agricultural sustainability. Int. J. Agric. Sustain. 2013, 11, 1-3. [CrossRef]

7. Velten, S.; Leventon, J.; Jager, N.; Newig, J. What is sustainable agriculture? A systematic review. Sustainability 2015, 7, 7833-7865. [CrossRef]

8. Haileslassie, A.; Craufurd, P.; Thiagarajah, R.; Kumar, S.; Whitbread, A.; Rathor, A.; Blummel, M.; Ericsson, P.; Kakumanu, K.R. Empirical evaluation of sustainability of divergent farms in the dryland farming systems of india. Ecol. Indic. 2016, 60, 710-723. [CrossRef]

9. Yazdanpanah, M.; Hayati, D.; Zamani, G.H.; Karbalaee, F.; Hochrainer-Stigler, S. Water management from tradition to second modernity: An analysis of the water crisis in Iran. Environ. Dev. Sustain. 2013, 15, 1605-1621. [CrossRef]

10. Baniasadi, M.; Zare Mehrjordi, M.R.; Mehrabi Boshrabadi, H.; Mirzaei, H.R.; Rezaei Estakhrooye, A. Assessing the environmental externalities of excessive groundwater withdrawals using the choice experiment method-a case study of Kerman, Iran. Appl. Ecol. Env. Res. 2016, 14, 683-696. [CrossRef]

11. Mehrabi Boshrabadi, H.; Villano, R.; Fleming, E. Technical efficiency and environmental-technological gaps in wheat production in Kerman province of Iran. Agric. Econ. 2008, 38, 67-76. [CrossRef]

12. Plan and Budget Organization of Kerman Province. Economic, Social and Cultural Report of Kerman Province 2015; Plan and Budget Organization of Kerman Province: Kerman, Iran, 2017.

13. Statistical Center of Iran. Available online: https:/ / www.amar.org.ir/ (accessed on 14 September 2017).

14. Reed, M.S.; Fraser, E.D.; Dougill, A.J. An adaptive learning process for developing and applying sustainability indicators with local communities. Ecol. Econ. 2006, 59, 406-418. [CrossRef]

15. Roy, R.; Chan, N.W. An assessment of agricultural sustainability indicators in Bangladesh: Review and synthesis. Environmentalist 2012, 32, 99-110. [CrossRef]

16. Gómez-Limón, J.A.; Sanchez-Fernandez, G. Empirical evaluation of agricultural sustainability using composite indicators. Ecol. Econ. 2010, 69, 1062-1075. [CrossRef]

17. Nambiar, K.; Gupta, A.; Fu, Q.; Li, S. Biophysical, chemical and socio-economic indicators for assessing agricultural sustainability in the Chinese coastal zone. Agric. Ecosyst. Environ. 2001, 87, 209-214. [CrossRef]

18. Hayati, D.; Ranjbar, Z.; Karami, E. Measuring agricultural sustainability. In Biodiversity, Biofuels, Agroforestry and Conservation Agriculture; Lichtfouse, E., Ed.; Springer: Dordrecht, The Netherlands, 2010; pp. 73-100.

19. Farshad, A.; Zinck, J.A. Assessing agricultural sustainability using the six-pillar model: Iran as a case study. Agroecosyst. Sustain. Dev. Pract. Strateg. 2001, 137-151.

20. Zinck, J.; Berroterán, J.; Farshad, A.; Moameni, A.; Wokabi, S.; Ranst, E.V. Approaches to assessing sustainable agriculture. J. Sustain. Agric. 2004, 23, 87-109. [CrossRef]

21. López-ridaura, S.; Keulen, H.V.; Van Ittersum, M.; Leffelaar, P. Multiscale methodological framework to derive criteria and indicators for sustainability evaluation of peasant natural resource management systems. Environ. Dev. Sustain. 2005, 7, 51-69. [CrossRef]

22. Vecchione, G. EU Rural Policy: Proposal and Application of an Agricultural Sustainability Index; Munich Personal RePEc Archive (MPRA) Paper no. 27032; MPRA: Munich, Germany, 2010.

23. Pourzand, F.; Bakhshoodeh, M. Technical efficiency and agricultural sustainability-technology gap of maize producers in Fars province of Iran. Environ. Dev. Sustain. 2014, 16, 671-688. [CrossRef]

24. Shannon, C.E.; Wiener, W. The Mathematical Theory of Communication (pp. 1-117); University of Illinois Press: Urbana, IL, USA, 1963. 
25. World Bank. Worldwide Governance Indicators; World Bank: Washington, DC, USA, 2017. Available online: http:/ / databank.worldbank.org/data/download/WGI_excel.zip (accessed on 21 September 2017).

26. Lio, M.; Liu, M.-C. Governance and agricultural productivity: A cross-national analysis. Food Policy 2008, 33, 504-512. [CrossRef]

27. Kaufmann, D.; Kraay, A.; Mastruzzi, M. The Worldwide Governance Indicators: Methodology and Analytical Issues; World Bank Policy Research Working Paper No. 5430; World Bank: Washington, DC, USA, 2010.

28. Kaufmann, D.; Kraay, A.; Mastruzzi, M. The worldwide governance indicators: Methodology and analytical issues. Hague J. Rule Law 2011, 3, 220-246. [CrossRef]

29. Chen, J. Rapid urbanization in China: A real challenge to soil protection and food security. CATENA 2007, 69, 1-15. [CrossRef]

30. Asadullah, M.N.; Rahman, S. Farm productivity and efficiency in rural Bangladesh: The role of education revisited. Appl. Econ. 2009, 41, 17-33. [CrossRef]

31. Reimers, M.; Klasen, S. Revisiting the role of education for agricultural productivity. Am. J. Agric. Econ. 2013, 95, 131-152. [CrossRef]

32. Odendo, M.; Obare, G.; Salasya, B. Factors responsible for differences in uptake of integrated soil fertility management practices amongst smallholders in western Kenya. Afr. J. Agric. Res. 2009, 4, 1303-1311.

33. OECD. Environmental Indicators for Agriculture: Methods and Results; OECD: Paris, France, 2001; Volume 3.

34. Cornia, G.A. Farm size, land yields and the agricultural production function: An analysis for fifteen developing countries. World Dev. 1985, 13, 513-534. [CrossRef]

35. Tilman, D.; Cassman, K.G.; Matson, P.A.; Naylor, R.; Polasky, S. Agricultural sustainability and intensive production practices. Nature 2002, 418, 671. [CrossRef] [PubMed]

36. Pretty, J.N.; Noble, A.D.; Bossio, D.; Dixon, J.; Hine, R.E.; Penning de Vries, F.W.; Morison, J.I. Resource-conserving agriculture increases yields in developing countries. Environ. Sci. Technol. 2006, 40, 1114-1119. [CrossRef]

37. Hazell, P.; Wood, S. Drivers of change in global agriculture. Philos. Trans. R. Soc. Lond. B 2008, 363, 495-515. [CrossRef]

38. Barrett, C.B.; Lee, D.R.; McPeak, J.G. Institutional arrangements for rural poverty reduction and resource conservation. World Dev. 2005, 33, 193-197. [CrossRef]

39. Kaufmann, D.; Kraay, A.; Mastruzzi, M. Governance Matters Vii: Aggregate and Individual Governance Indicators 1996-2007; World Bank: Washington, DC, 2007.

40. Pretty, J.; Ward, H. Social capital and the environment. World Dev. 2001, 29, 209-227. [CrossRef]

41. Freudenberg, M. Composite Indicators of Country Performance: A Critical Assessment; OECD Science, Technology and Industry Working Papers, 2003/16; OECD: Paris, France, 2003.

42. OECD, Organization for Economic Co-operation and Development-JRC, Joint Research Centre. Handbook on Constructing Composite Indicators: Methodology and User Guide; OECD: Paris, France, 2008.

43. Van Kooten, G.C.; Schoney, R.A.; Hayward, K.A. An alternative approach to the evaluation of goal hierarchies among farmers. West. J. Agric. Econ. 1986, 40-49.

44. Boender, C.; De Graan, J.; Lootsma, F. Multi-criteria decision analysis with fuzzy pairwise comparisons. Fuzzy Set. Syst. 1989, 29, 133-143. [CrossRef]

45. Mendoza, G.A.; Sprouse, W. Forest planning and decision making under fuzzy environments: An overview and illustration. Forest Sci. 1989, 35, 481-502.

46. Ells, A.; Bulte, E.; Van Kooten, G.C. Uncertainty and forest land use allocation in British Columbia: Vague priorities and imprecise coefficients. Forest Sci. 1997, 43, 509-520.

47. Basarir, A.; Gillespie, J.M. Multidimensional goals of beef and dairy producers: An inter-industry comparison. Agric. Econ. 2006, 35, 103-114. [CrossRef]

48. Berkhout, F.; Verbong, G.; Wieczorek, A.J.; Raven, R.; Lebel, L.; Bai, X. Sustainability experiments in Asia: Innovations shaping alternative development pathways? Environ. Sci. Policy 2010, 13, 261-271. [CrossRef]

49. Saaty, T.L. The Analytic Hierarchy Process: Planning, Priority Setting, Resource Allocation; McGraw-Hill International Book Company: New York, NY, USA, 1980.

50. Saaty, T.L. How to make a decision: The analytic hierarchy process. Eur. J. Oper. Res. 1990, 48, 9-26. [CrossRef] 
51. Golden, B.L.; Wasil, E.A.; Levy, D.E. Applications of the analytic hierarchy process: A categorized, annotated bibliography. In The Analytic Hierarchy Process; Golden, B.L., Wasil, E.A., Harker, P.T., Eds.; Springer: Berlin, Germany, 1989; pp. 37-58.

52. Gómez-Limón, J.A.; Riesgo, L. Alternative approaches to the construction of a composite indicator of agricultural sustainability: An application to irrigated agriculture in the Duero basin in Spain. J. Environ. Manag. 2009, 90, 3345-3362. [CrossRef] [PubMed]

53. Nardo, M.; Saisana, M.; Saltelli, A.; Tarantola, S.; Hoffman, A.; Giovannini, E. Handbook on Constructing Composite Indicators: Methodology and User Guide; OECD Statistics Working Paper; OECD: Paris, France, 2005.

54. Nardo, M.; Saisana, M.; Saltelli, A.; Tarantola, S. Tools for Composite Indicators Building; Joint Research Centre-European Commission: Ispra, Italy, 2005.

55. Allahyari, M.S.; Damalas, C.A.; Ebadattalab, M. Determinants of integrated pest management adoption for olive fruit fly (Bactrocera oleae) in Roudbar, Iran. Crop Prot. 2016, 84, 113-120. [CrossRef]

56. Bell, S.; Morse, S. Sustainability Indicators: Measuring the Immeasurable, 2nd ed.; Earthscan: London, UK, 2008; ISBN 978-1-84407-299-6.

57. Bell, S.; Morse, S. Measuring Sustainability: Learning from Doing; Routledge: London, UK, 2013.

58. MacPherson, N. Assessing progress toward sustainability: A new approach. In A Sustainable World: Defining and Measuring Sustainable Development; Trzyna, T.C., Osborn, J.K., Eds.; IUCN: London, UK, 1995.

59. Prescott-Allen, R. Barometer of sustainability: Measuring and communicating wellbeing and sustainable development. In An Approach to Assessing Progress toward Sustainability: Tools and Training Series; IUCN: Gland, Switzerland, 1997.

60. Ko, T.G. Development of a tourism sustainability assessment procedure: A conceptual approach. Tour. Manag. 2005, 26, 431-445. [CrossRef]

61. Rigby, D.; Woodhouse, P.; Young, T.; Burton, M. Constructing a farm level indicator of sustainable agricultural practice. Ecol. Econ. 2001, 39, 463-478. [CrossRef]

62. Van Loon, G.W.; Patil, S.; Hugar, L. Agricultural Sustainability: Strategies for Assessment; SAGE: New Delhi, India, 2005.

(C) 2018 by the authors. Licensee MDPI, Basel, Switzerland. This article is an open access article distributed under the terms and conditions of the Creative Commons Attribution (CC BY) license (http:/ / creativecommons.org/licenses/by/4.0/). 